Serbest, Kamile (2020). Uygurların Somut Olmayan Kültürel Mirası: Kazakistan Örneği Projesi ve Çıktıları Üzerine, Uluslararası Uygur Araştırmaları Dergisi, Sayı: 2020/15, s. 225-228.

DOI: 10.46400/uygur.729557

\title{
Uygurların Somut Olmayan Kültürel Mirası: Kazakistan Örneği Projesi ve Çıktıları Üzerine
}

[Kitap Tanitım ve Değerlendirme / Book Review]

Kamile SERBEST*

Geliş Tarihi: 29.04.2020

Kabul Tarihi: 18.05.2020

1972 yılında, kültürel somut yapıları ve doğal çevreyi korumayı amaçlayan Dünya Kültürel ve Doğal Mirasının Korunması Sözleșmesi'nin kabul edilmesi ile birlikte (Türkiye 1983 yılında taraf olmuștur), yapılan çalışmalardan hareketle geçmişten günümüze aktarılan ancak çeşitli etkenler sebebiyle değişime uğrayan, "dille aktarılan, kuşaktan kuşağa usta çırak ilişkisi içinde ve okul dışı koşullarda yani geleneksel ortamlarda görerek öğrenilen" (Oğuz, 2009: 53, 54) yaşayan miras ya da somut olmayan kültürel mirasın da korunması gerektiği fark edilmiştir. Böylelikle "Somut olmayan kültürel miras" teriminin, "somut kültürel miras" çalışmalarının doğal bir sonucu olarak UNESCO'nun "kültür varlıklarının korunması" için yürüttüğü programlar sırasında (Oğuz 2009: 53) doğduğunu söylemek mümkündür. Bu amaçla, "bir toplumun kendi kültürel kimliğinin bir parçası olarak gördüğü ve kuşaktan kuşağa aktarmak suretiyle günümüze kadar getirdiği somut olmayan kültürel miraslarını korumasına ve gelecek kuşaklara aktarmasına katkı sağlayacak yol, yöntem ve imkânları" (Oğuz, 2009: 8) tanımlayan Somut Olmayan Kültürel Mirasın Korunması Sözleșmesi, 17 Ekim 2003 32. Genel Konferansında UNESCO tarafından kabul edilmiştir. Türkiye ise bu sözleşmeye 27 Mart 2006 yılında taraf olmuştur (URL-1). Türkiye'de bu bağlamda halkbilimi, turizm gibi bölümlerde dersler verilmekte, yüksek lisans ve doktora programları açılmakta, bunun yanı sıra belirli bölgelerin SOKÜM ürünlerine yer veren çalışmalar yapılmaktadır. Bu konudaki bazı çalışmalar ülkemiz sınırlarını da aşmış olup Türk dünyasının farklı coğrafya ve boylarına uzanmıştır. Bu çalışmalardan biri "Uygurların Somut Olmayan Kültürel Mirası: Kazakistan Örneği" adlı projedir. Söz konusu çalışma, genelde Türk dünyası, özelde Uygur Türkleri üzerine yapılan ilk çalışma olması bakımından dikkate değerdir.

Tarihi süreçte yaşadıkları coğrafyada birçok milletle etkileşim içinde olan Uygur Türkleri, kültürel zenginliği dolayısıyla Türk boyları arasında farklı bir yere sahiptir. "Çin'in Uygur Özerk Bölgesi'nde yaşayan Uygurlar, son yüzyllda çeşitli siyasi ve sosyal nedenlerle Kazakistan, Kırgızistan, Özbekistan, Türkiye gibi ülkelere göç etmek zorunda kalmıştır. 1870'li yıllarda Çin'den Kazakistan'a başlayan Uygurların göçü, 1960'lı yıllara kadar devam etmiştir. Günümüzde, 250.000 civarında Uygur nüfusunun bulunduğu coğrafyalardan biri olan Kazakistan, onların kültürel miraslarını sürdürmeleri ve milli kimliklerini korumaları için uygun bir ortam olmuştur" (Öger, 2019: 15). Bu nedenle başta Doğu Türkistan'da yaşayan Uygur Türkleri olmakla birlikte Kazakistan gibi diğer coğrafyalarda yaşayan Uygur Türklerinin kültürel zenginliklerin yaşatılması, aktarılması ve diğer Türk boyları tarafından bilinmesi elzemdir. "Uygurların Somut Olmayan Kültürel Mirası: Kazakistan Örneği" isimli proje de bu amaçla hayata geçirilen bir çalışmadır. Yurtdışı Türkler ve Akraba Topluluklar Başkanlığı tarafından desteklenen ve Doç. Dr. Adem Öger'in yürütücülüğünü yaptığı projenin çıktıları, Türk Halk Bilimi ve SOKÜM çalışmaları açısından önemlidir.

\footnotetext{
* Doktora Öğrencisi, Hacettepe Üniversitesi, Sosyal Bilimler Enstitüsü, Türk Halkbilimi Anabilim Dalı, e-posta: kamile.serbest0@gmail.com Orcid: 0000-0001-9859-3120
} 
Kazakistan'ın Almatı eyaleti sınırları içinde Uygur Türklerinin yaşadı̆̆ı bölgelerde yapılan saha çalışmasında derlenen verilerden hareketle oluşturulan, "Uygurların Somut Olmayan Kültürel Mirası Kazakistan Örneği" isimli eser, projenin çıktılarından biridir. Bu eserin dışında "Kazakistan'da Yayımlanan Uygurca Eserler Kataloğu" adlı eser ve "Kazakistan Uygurları 1-2" isimli iki bölümden oluşan belgesel film proje kapsamında bilim âlemine kazandırılmıştır.

Uygurların Somut Olmayan Kültürel Mirası Kazakistan Örneği. (2019). (Ed.: Adem Öger), Ankara: Girişim Ajans Matbaa, 461 s.

\begin{abstract}
"Uygurlarin Somut Olmayan Kültürel Mirası Kazakistan Örneği" isimli çalışma; Türkçe, Uygurca ve Kazakça olarak üç dilde hazırlanmıştır. Eser; "Sunuş", "Ön söz", "Giriş" UNESCO'nun "Somut Olmayan Kültürel Miras Sözleşmesi'nde ifade edilen başlıklardan hareketle hazırlanan; "Sözlü Anlatımlar ve Gelenekler", "Gösteri Sanatları", Toplumsal Uygulamalar, Ritüeller ve Şölenler", "Doğa ve Evrenle İlgili Bilgi ve Uygulamalar", "El Sanatları Geleneği" ve "Kaynaklar" bölümlerinden oluşmaktadır. "Sözlü Anlatımlar ve Gelenekler" başlığı altında, Uygur Türkleri arasında geçmișten günümüze aktarılan; ninni, masal, destan, halk hikâyesi, efsane, fikra, bilmece, mani, ağıt, türkü, tekerleme, atasözü ve deyim, dua gibi sözlü kültür içerisinde önemli bir yere sahip olan türlere yer verilmiştir. "Gösteri Sanatları" başlığı altında, Uygur on iki makamı, halk çalgıları ve halk

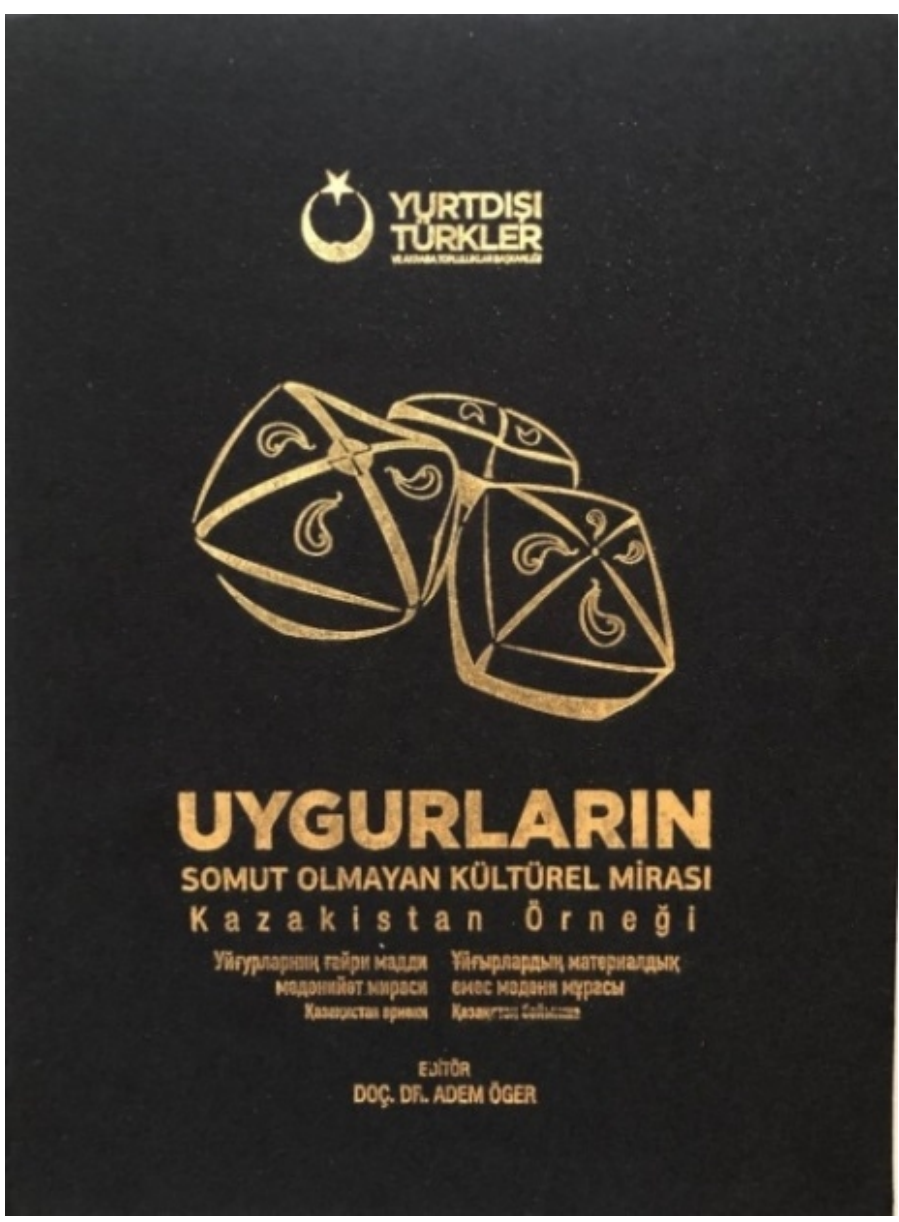
dansları; Sama dansı, Dolan dansı, Samaver-çine dansı anlatılmıştır. "Toplumsal Uygulamalar, Ritüeller ve Şölenler" başlığı altında ise Uygurların geçiş dönemi uygulamaları ve hatim töreni, meşrepler, çocuk oyunları ve nevruz bayramı ele alınmıştır. "Doğa ve Evrenle İlgili Bilgi ve Uygulamalar" bölümünde, halk hekimliği, halk inanışları, rüya tabiri ve Uygurların geleneksel lezzetlerine ait bilgiler bulunmaktadır. Son bölüm olan "El Sanatları" kısmında ise birçok çalışmaya konu olan; demircilik, tenekecilik, ayakkabıcılık, fırıncllık, aşçllı, süpürgecilik, terzilik, halk mimarisi gibi Uygurların geleneksel mesleklerine yer verilmiştir. Her bölüm, saha çalışmasında çekilen fotoğraflarla desteklenmiştir. Eser, Uygur Türklerinin duygu, düşünce, inanç, yaşayış tarzı hakkında bilgi vermesi, kültürel miraslarının kayıt altına alınması ve yapılacak çalışmalara kaynaklık etmesi bakımından önem arz etmektedir.
\end{abstract}


Kazakistan'da Yayımlanan Uygurca Eserler Kataloğu. (2019). (Ed.: Adem Öger), Ankara: Girişim Ajans Matbaa, 177 s.

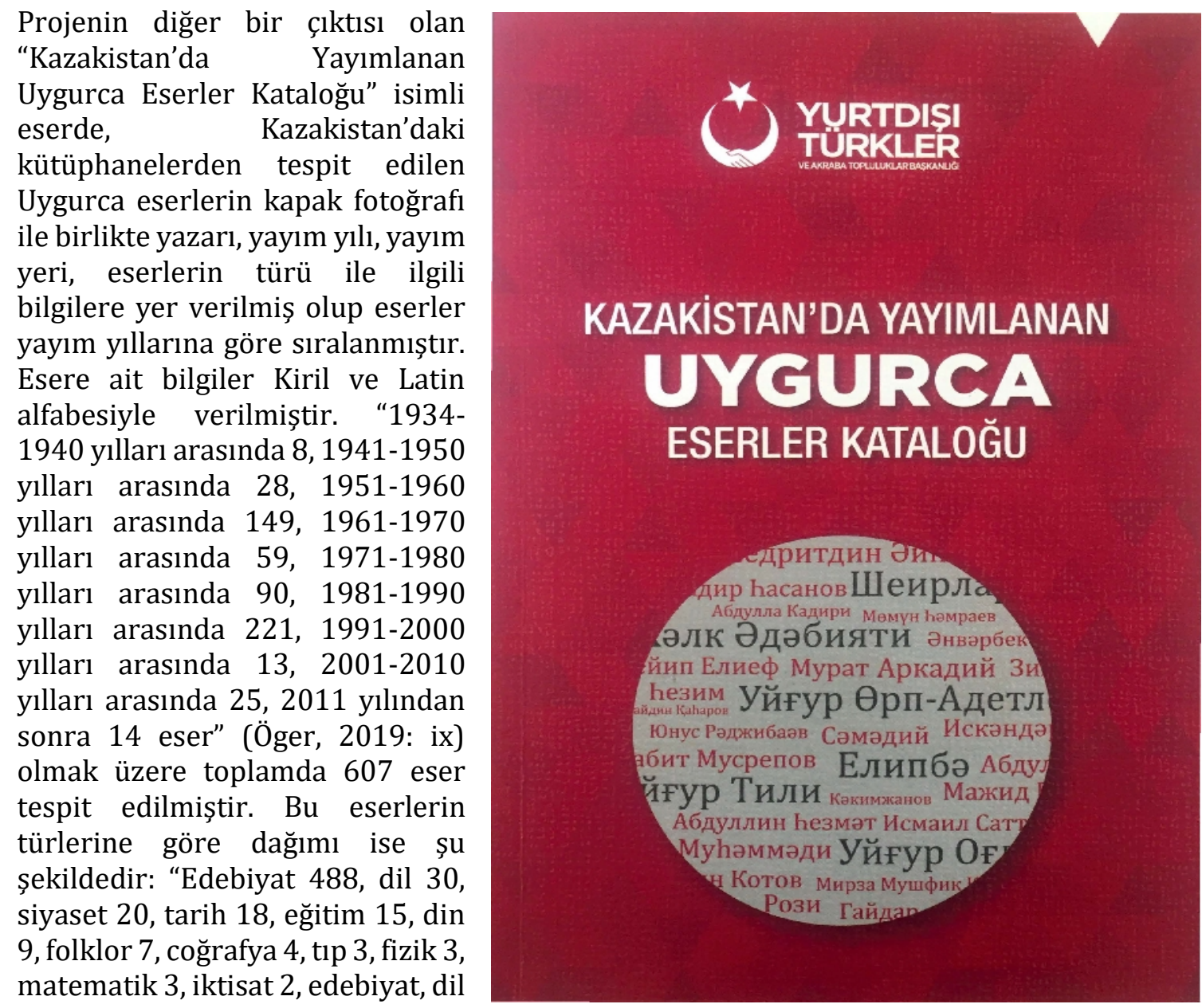
ve tarih 1 , biyoloji 1 , astronomi 1 , müzik 1, kimya 1" (Öger 2019: ix). 607 eserin yer aldığı katalog çalışması, Kazakistan dışında Uygurlar üzerine çalışma yapanlar için kolaylık sağlaması açısından büyük önem taşımaktadır.

\section{Kazakistan Uygurları 1-2 (Belgesel Film)}

"Kazakistan Uygurları 1-2" isimli belgesel film, projenin diğer çıktılarından biridir. Somut Olmayan Kültürel Miras bağlamında hazırlanan belgeselin 1. Bölüm'ünde, Kazakistan'da yaşayan Uygurların günlük hayatları, geçim kaynakları, inanış ve uygulamaları, halk mimarisi, sözlü kültür ürünleri, mutfak kültürü, çocuk oyunları, doğum, sünnet, düğün ve ölüm adetleri konu edinilmiștir. Belgeselin 2. Bölümü'nde ise Uygurların geleneksel meslekleri içerisinde önemli bir yer tutan demircilik, terzilik, ayakkabıcılık, firıncılık, kabak oymacılığı (kapak çömüş); sanatsal etkinliklerin icra edildiği ve 2010 yılında UNESCO'nun Somut Olmayan Kültürel Miras listesine dâhil edilen Uygur meşrepleri, Uygur On İki Makamı; Sama, Samaver-çine gibi halk dansları ve Uygur kültürünü tuvallerine döken ressamlar tanıtılmıştır. 
"Uygurlarin Somut Olmayan Kültürel Mirası: Kazakistan Örneği" projesi, Türkiye'de Anadolu dışındaki bir Türk boyunun somut olmayan kültürel mirasını görselleri ile birlikte bir bütünlük içinde ele alan ilk çalışma olması bakımından dikkate değerdir. Çıktıları bakımından da oldukça zengin olan çalışma, Uygur kültürünü her yönüyle ele alması bakımından Türk boyları üzerine yapılacak çalışmalara örnek ve kaynak teşkil edecektir. Söz konusu çalışmaları ortaya koymak için emek harcayan Proje Yürütücüsü ve Editör Doç. Dr. Adem Öger bașta olmak üzere proje ekibine teșekkür eder, projenin çıktılarını yayına dönüştürüp okuyucu ve izleyicisi ile buluşturan YTB'nin bu tarz çalışmalara desteklerinin devamını dileriz.

\section{Kaynakça}

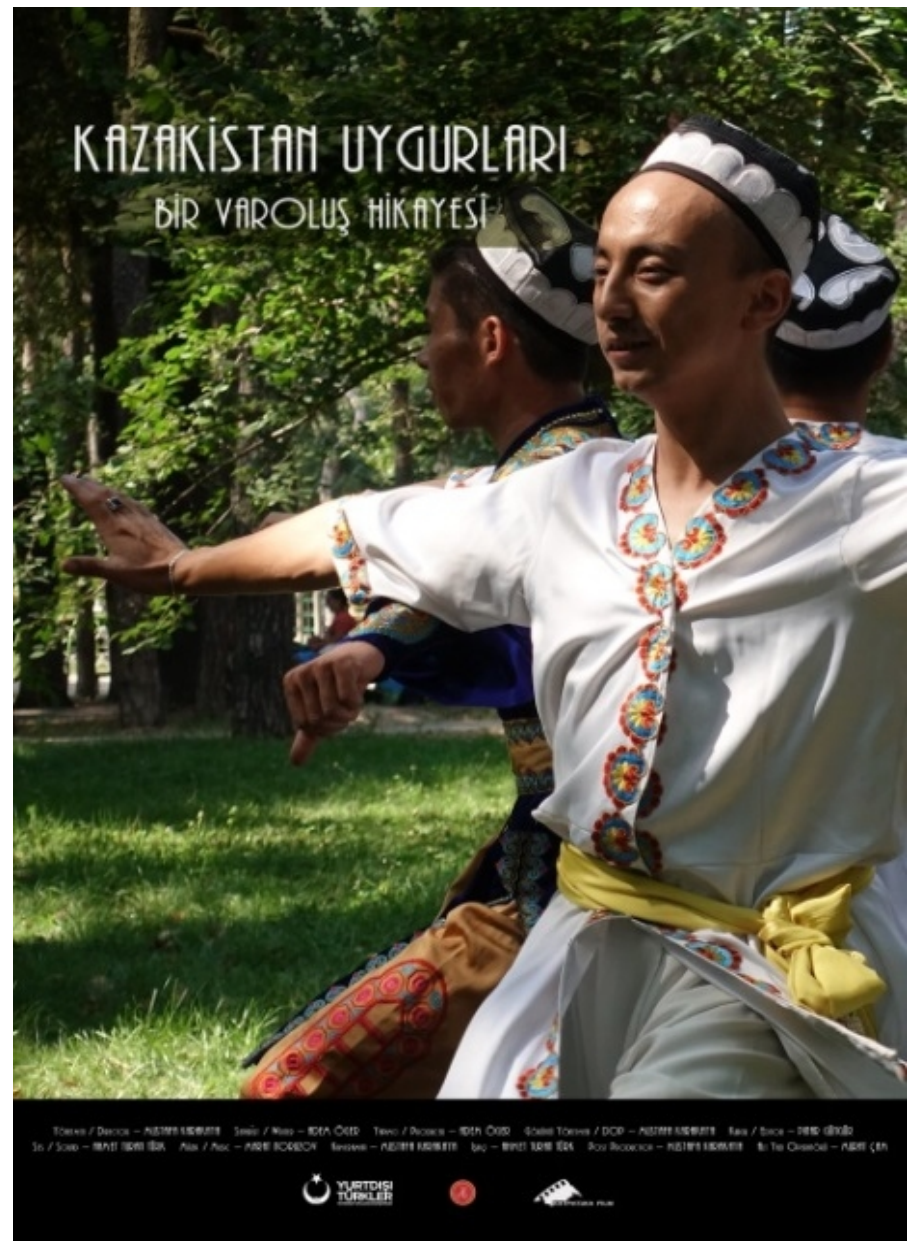

KAZAKISTAN'DA YAYIMLANAN UYGURCA ESERLER KATALOĞU. (2019). (Ed.: Adem Öger), Ankara: Girişim Ajans Matbaa.

UYGURLARIN SOMUT OLMAYAN KÜLTÜREL MIRASI KAZAKISTAN ÖRNEĞİ. (2019). (Ed.: Adem Öger), Ankara: Girişim Ajans Matbaa.

OĞUZ, M. Öcal (2009). Somut Olmayan Kültürel Miras Nedir? Ankara: Geleneksel Yayıncılık. İnternet Kaynakları:

* URL-1: http://www.unesco.org.tr/ (Erişim: 26.03.2020) 